\title{
openheart Single-centre cohort study of gender influence in coronary CT angiography in patients with a low to intermediate pretest probability of coronary heart disease
}

Kirsten Schou Nørgaard, ${ }^{1}$ Christin Isaksen, ${ }^{1}$ Jørgen Selmer Buhl, ${ }^{1}$ Jane Kirk Johansen, ${ }^{1}$ Agnete Hedemann Nielsen, ${ }^{2}$ Aage Nørgaard, ${ }^{1}$ Grazina Urbonaviciene, ${ }^{2}$ Jes S Lindholt, ${ }^{3}$ Lars Frost ${ }^{2}$

To cite: Nørgaard KS, Isaksen C, Buhl JS, et al. Single-centre cohort study of gender influence in coronary CT angiography in patients with a low to intermediate pretest probability of coronary heart disease. Open Heart 2015;2:e000233. doi:10.1136/openhrt-2014000233

Received 16 December 2014 Revised 16 June 2015 Accepted 22 June 2015

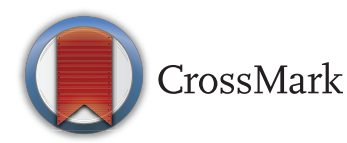

\footnotetext{
${ }^{1}$ Diagnostic Centre, University Research Clinic for Innovative Patient Pathways, Silkeborg Regional Hospital, Silkeborg, Denmark

${ }^{2}$ Institute for Clinical Medicine, Aarhus University Hospital, Silkeborg, Denmark ${ }^{3}$ Department of Cardiothoracic and Vascular Surgery, Centre for Individualised Medicine in Arterial Disease, Odense University Hospital, Odense, Denmark
}

Correspondence to Dr Lars Frost; larfrost@rm.dk

\section{ABSTRACT}

Background: In 'real-world' patient populations undergoing coronary CT angiography (CCTA), it is unclear whether a correlation exists between gender, coronary artery calcium (CAC) score and subsequent referral for invasive coronary angiography and coronary revascularisation. We therefore investigated the relationship between gender, CAC and use of subsequent invasive coronary angiography and coronary revascularisation in a cohort of patients with chest discomfort and low to intermediate pretest probability of coronary artery disease who underwent a CCTA at our diagnostic centre.

Methods: This is a cohort study that included patients examined between 2010 and 2013. Data were obtained from the Western Denmark Heart Registry. The followup ended 11 March 2014.

Results: A total of 3541 people (1621 men and 1920 women) were examined by CCTA. The rate of invasive coronary angiography during follow-up was $28.5 \%$ in men versus $18.3 \%$ in women $(p<0.001)$. The rate of coronary revascularisation during follow-up was $11.4 \%$ in men versus $5.1 \%$ in women $(p<0.001)$. The CACadjusted HR in women versus men was $0.98(95 \% \mathrm{Cl}$ 0.85 to 1.13 ) for invasive coronary angiography and $0.73(95 \% \mathrm{Cl} 0.57$ to 0.93$)$ for coronary revascularisation. Further adjustment for age and other risk factors did not change these estimates.

Conclusions: Women had a lower CAC score than men and a corresponding lower rate of invasive coronary angiography. The risk of coronary revascularisation was modestly reduced in women, irrespective of CAC. This may reflect a gender-specific difference in coping with chest discomfort, genderspecific referral bias for CCTA, and/or a gender-specific difference in the balance between coronary calcification and obstructive coronary heart disease.

\section{INTRODUCTION}

Several studies have demonstrated that coronary artery calcium (CAC) is a marker for

\section{KEY MESSAGES}

What is already known on this subject?

- In 'real-world' patient populations undergoing coronary CT angiography (CCTA), it is unclear whether a correlation exists between gender, coronary artery calcium (CAC) score and subsequent referral for invasive coronary angiography and coronary revascularisation.

What does this study add?

- We found that women had a lower CAC score and underwent less invasive coronary angiography and revascularisation than men. However, in multivariable models, we found that CAC rather than gender determined the use of invasive coronary angiography after CCTA, although the risk of coronary revascularisation was reduced in women, irrespective of CAC.

How might this impact on clinical practice?

- The process of triaging women with chest pain needs further scientific investigation.

atherosclerosis and hence for coronary artery disease $(\mathrm{CAD}){ }^{1}$ ECG-synchronised coronary CT angiography (CCTA) using fast scanners is a reliable method for estimating CAC. This is usually accomplished by summing all lesions using the Agatston Score. ${ }^{2}$

The degree of CAC is affected by age and gender as well as other well-established risk factors for the development of CAD. A number of studies have demonstrated an incremental increase in CAC with age in both men and women as well as significantly higher CAC in men than women. ${ }^{3-5}$ Most studies have been performed in populationbased samples of healthy individuals who underwent CCTA screening. Age, gender 
and race/ethnicity-specific percentiles of CAC have been established in people who are free of known CAD at the time of investigation. ${ }^{6}{ }^{7}$ However, in 'real-world' patient populations, it is unclear if there is a correlation between gender, CAC and the clinical decisions that are made about subsequent referrals for invasive coronary angiography and coronary revascularisation. We therefore investigated the relationship between gender and CAC in a cohort of patients with chest discomfort and low to intermediate pretest probability of CAD who underwent a CCTA at our diagnostic centre. We also examined CAC and referrals by gender for subsequent invasive coronary angiography and revascularisation.

\section{METHODS}

\section{Patient population, data source and study period}

The patient population consisted of all individuals with chest discomfort and/or dyspnoea and low to intermediate pretest probability of CAD admitted for their first CCTA at the Silkeborg Diagnostic Centre between 1 January 2010 and 31 December 2013 and whose data had been reported to The Western Denmark Heart Registry. The Western Denmark Heart Registry is a validated clinical database within a population-based healthcare system and covers a population of 3.3 million. ${ }^{8}$ The database was initiated in 1999 and includes invasive procedures and, from 2008, also CCTA. ${ }^{8} 9$ Demographics, vital status, clinical data, data related to the CCTA, and data related to invasive procedures were obtained from the Western Denmark Heart Registry on 11 March 2014, which is also the date that follow-up ended. The Western Denmark Heart Registry holds no information on emigration status. The study was approved by the Danish Data Protection Agency. Danish authorities do not require informed consent when a study is based on registry data. The study therefore did not require approval from an ethics committee.

The study period was chosen because of the nearly complete reporting of patient data to the Western Denmark Heart Registry from 1 January $2010 .^{9}$

\section{CT technique}

Patients were told not to eat for at least $2 \mathrm{~h}$ before the examination and to avoid coffee, tea and tobacco. They were asked to take 50-100 $\mathrm{mg}$ atenolol in the morning of the day of the examination. For those with contraindications to $\beta$-blockers, we used ivabradine $5-7.5 \mathrm{mg}$. If the heart rate exceeded 65 beats/min during the examination, we added $2.5-20 \mathrm{mg}$ metoprolol intravenously.

We used a 64 multislice spiral CT scanner (Philips Brilliance 64; Philips Medical Systems, The Netherlands) until June 2010 and thereafter a 320 multislice dynamic volume CT scanner (Aquillion One; Toshiba Medical Systems, Japan), which shortened the scan time. The new scanner also uses ECG-synchronised data sampling, which further reduces the radiation dose. In the summer of 2012, the Toshiba scanner was upgraded from a filtered back projection to an iterative reconstruction and dose modulation. This resulted in a $14 \%$ reduction in the radiation dose from a mean of 3.1 to $2.7 \mathrm{mSv}$. In total, the change of CT scanner together with the upgrade resulted in a $50 \%$ reduction in the median radiation dose from 4.2 to $2.2 \mathrm{mSv}^{10}$

The CCTA examination started with a calcium scan without contrast, which produced a CAC score. Then, $800 \mu \mathrm{g}$ nitroglycerine was administered sublingually to dilate the coronary arteries 2 min before the next scan. A bolus of $60-90 \mathrm{~mL}$ non-ionic contrast (Iomeron $350 \mathrm{mg} / \mathrm{mL}$; Bracco Imaging Scandinavia $\mathrm{AB}$ ) was then administered at an infusion rate of $5-6 \mathrm{~mL} / \mathrm{s}$ via a cubital vein. CT recordings with and without contrast were obtained during breath holds of $10 \mathrm{~s}$ with simultaneous ECG recording. Subsequently, data were transferred to a Vitrea Advanced Workstation (Vital Images, USA). Coronary calcium was defined as an attenuation of $\geq 130$ Hounsfield units. The CAC score was estimated using the Vitrea Workstation and a calcium analysis programme. A summed calcium score based on data from all coronary arteries, the Agatston Score, ${ }^{2}$ was calculated for each patient. Contrast infusion was omitted when the Agatston Score exceeded 1000, in which case the patients were admitted for a perfusion scan or invasive coronary angiography.

After completion of the CT scan with contrast infusion, all coronary artery segments were reconstructed on a Vitrea Workstation. The coronary arteries were classified as normal, non-obstructive (stenosis $<50 \%$ ) or obstructive (stenosis $\geq 50 \%$ ).

Coronary CT angiograms were analysed by cardiologists with a level 2 certification (American Society of Cardiovascular CT Accreditation).

\section{Statistical analysis}

Categorical variables are presented as percentages, and continuous variables as medians with 10 th and 90th centiles in parentheses. We used Pearson's $\chi^{2}$ test for categorical variables and the Mann-Whitney test for continuous variables.

Data were analysed in Cox's proportional hazards regression models. We adjusted for risk factors and for proxies of risk factors for coronary heart disease such as age, smoking, CAC, diabetes mellitus, medical treatment for hypertension and cholesterol-lowering treatment. An invasive coronary angiography or a coronary revascularisation marked the end of the observation time, and the observation time was censored by death or the date that follow-up ended on 11 March 2014. The proportionality assumptions of the models were evaluated using Schoenfeld residuals and graphically. We considered $\mathrm{p}<0.05$ to be significant. The study power was $90-100 \%$ for the detection of a $5 \%$ absolute difference between men and women in the range from $5 \%$ to $35 \%$ of the incidence rates of invasive coronary angiography or coronary revascularisation, given a risk of type I error of $5 \%$ 
Table 1 Demographic and clinical characteristics of men and women

\begin{tabular}{|c|c|c|c|}
\hline & Women $(n=1920)$ & Men $(n=1621)$ & p Value \\
\hline Age & $61.0(46.0-73.0)$ & $58.0(42.0-71.0)$ & $<0.001$ \\
\hline Height (cm) & $166(158-174)$ & $180(170-187)$ & $<0.001$ \\
\hline Weight $(\mathrm{kg})$ & $70(56-90)$ & $86(71-105)$ & $<0.001$ \\
\hline Body mass index $\left(\mathrm{kg} / \mathrm{m}^{2}\right)$ & $25.3(20.8-32.8)$ & $26.8(22.8-32.4)$ & $<0.001$ \\
\hline Smoking & & & $<0.001$ \\
\hline Never & $45.9 \%$ & $34.3 \%$ & \\
\hline Former & $34.7 \%$ & $42.0 \%$ & \\
\hline Current & $19.4 \%$ & $23.8 \%$ & \\
\hline Family history of ischaemic heart disease & $53.0 \%$ & $45.4 \%$ & $<0.001$ \\
\hline Diabetes mellitus & $6.4 \%$ & $9.2 \%$ & 0.002 \\
\hline Cholesterol-lowering treatment & $32.3 \%$ & $35.9 \%$ & 0.03 \\
\hline Systolic blood pressure (mm Hg) & $135(114-165)$ & $137(118-160)$ & 0.34 \\
\hline Diastolic blood pressure $(\mathrm{mm} \mathrm{Hg})$ & $80(68-94)$ & $82(70-95)$ & $<0.001$ \\
\hline Medical treatment for hypertension & $40.0 \%$ & $37.7 \%$ & 0.16 \\
\hline Left ventricular ejection fraction & $60(60-65)$ & $60(60-65)$ & $<0.001$ \\
\hline Plasma creatinine $(\mu \mathrm{mol} / \mathrm{L})$ & $66(54-82)$ & 82 (67-99) & $<0.001$ \\
\hline \multicolumn{4}{|c|}{$\begin{array}{l}\text { Values are medians with 10th and 90th centiles in parentheses for continuous variables and percentages for categorical variables. The test } \\
\text { used for categorical variables was Pearson's } \chi^{2} \text { test. The test used for continuous variables was the Mann-Whitney test. Number of missing } \\
\text { values: height, 152; weight, 141; body mass index, 159; smoking, 136; family history of ischaemic heart disease, 174; diabetes mellitus, } 110 \text {; } \\
\text { cholesterol-lowering treatment, 57; systolic blood pressure, 223; diastolic blood pressure, 225; medical treatment for hypertension, } 82 ; \text { left } \\
\text { ventricular ejection fraction, 210; plasma creatinine, } 319 \text {. }\end{array}$} \\
\hline
\end{tabular}

and risk of type II error of $20 \%$. All analyses were performed using Stata V.12.0.

\section{RESULTS}

During the study period, 1920 women (median age 61 years) and 1621 men (median age 58 years) underwent a CCTA (tables 1 and 2). Women were older and more often had a family history of ischaemic heart disease. The median CAC score (10th-90th centiles) was $0 \quad(0-351)$ in women versus $33(0-701)$ in men
( $\mathrm{p}<0.001)$. Total observation time was 5230 years (mean 1.5) for invasive coronary angiography and 6271 years (mean 1.8) for coronary revascularisation. Table 2 and figure 1 show that $18.3 \%$ of women and $28.5 \%$ of men had an invasive coronary angiography during follow-up ( $p<0.001)$. In women, $4.0 \%$ had a percutaneous coronary revascularisation versus $8.9 \%$ of men $(p<0.001)$, and $1.3 \%$ of women and $3.2 \%$ of men had coronary artery bypass surgery $(\mathrm{p}<0.001)$. The cumulative rate of any coronary revascularisation by sex is shown in figure 2 and was $5.1 \%$ in women versus $11.4 \%$ in men $(p<0.001)$.

Table 2 Characteristics in men and women in relation to CCTA and follow-up

\begin{tabular}{|c|c|c|c|}
\hline & Women $(n=1920)$ & Men $(n=1621)$ & p Value \\
\hline \multicolumn{4}{|l|}{ CCTA } \\
\hline Volume of contrast (mL) & $60(60-80)$ & $80(60-90)$ & $<0.001$ \\
\hline Radiation dose (mSv) & $2.6(1.2-6.4)$ & $3.3(1.6-8.3)$ & $<0.001$ \\
\hline CAC score (Hounsfield units) & $0(0-351)$ & $33(0-701)$ & $<0.001$ \\
\hline CAC score 0 & 57.0 & 37.6 & \\
\hline CAC score 1-99 & 21.8 & 26.5 & \\
\hline CAC score $100-399$ & 11.8 & 17.1 & \\
\hline CAC score 400-999 & 5.6 & 12.4 & \\
\hline CAC score $\geq 1000$ & 3.7 & 6.5 & $<0.001$ \\
\hline \multicolumn{4}{|l|}{ Consequence of CCTA } \\
\hline Referred for coronary angiography & $15.5 \%$ & $24.4 \%$ & $<0.001$ \\
\hline Referred for perfusion scan & $4.0 \%$ & $5.3 \%$ & 0.07 \\
\hline \multicolumn{4}{|c|}{ Proportion having coronary angiography or coronary revascularisation during follow-up } \\
\hline Coronary angiography & $18.3 \%$ & $28.5 \%$ & $<0.001$ \\
\hline Percutaneous coronary revascularisation & $4.0 \%$ & $8.9 \%$ & $<0.001$ \\
\hline Coronary artery bypass surgery & $1.3 \%$ & $3.2 \%$ & $<0.001$ \\
\hline
\end{tabular}




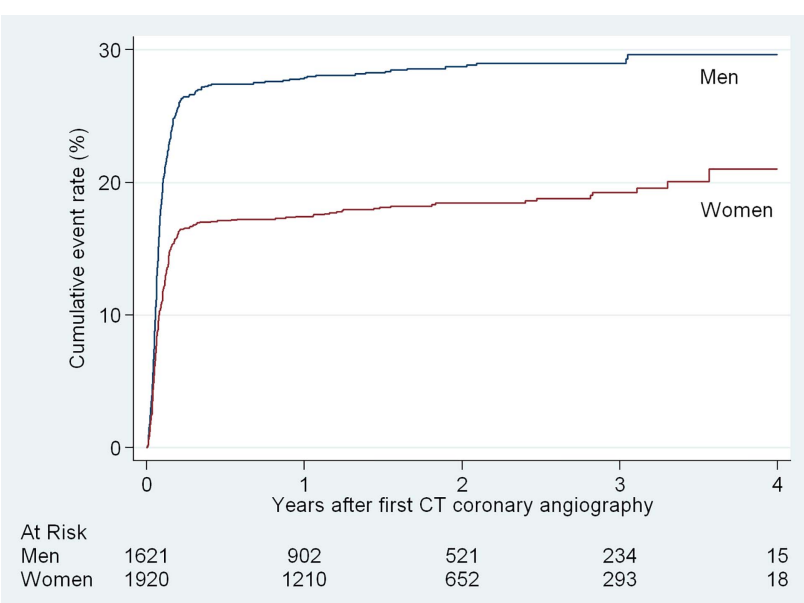

Figure 1 Cumulative rate of invasive coronary angiography by sex.

The higher cumulative rates of invasive coronary angiography by higher categories of CAC score are shown in figure 3. The CAC-score-adjusted HRs $(95 \%$ CI) for women versus men were 0.98 (0.85 to 1.13 ) for invasive coronary angiography and 0.73 (0.57 to 0.93 ) for coronary revascularisation. Further adjustment for age, smoking, diabetes mellitus, treatment for hypertension, and cholesterol-lowering treatment did not change risk estimates (table 3). We found no effect modification by sex on the risk of invasive coronary angiography and coronary revascularisation by increasing CAC score.

\section{DISCUSSION}

Among the 1920 women and 1621 men examined by CCTA in the period 1 January 2010 to 31 December 2013, women had a lower CAC score and underwent less invasive coronary angiography and revascularisation than men. However, in multivariable models, we found that CAC rather than gender determined the use of invasive coronary angiography after CCTA, although the

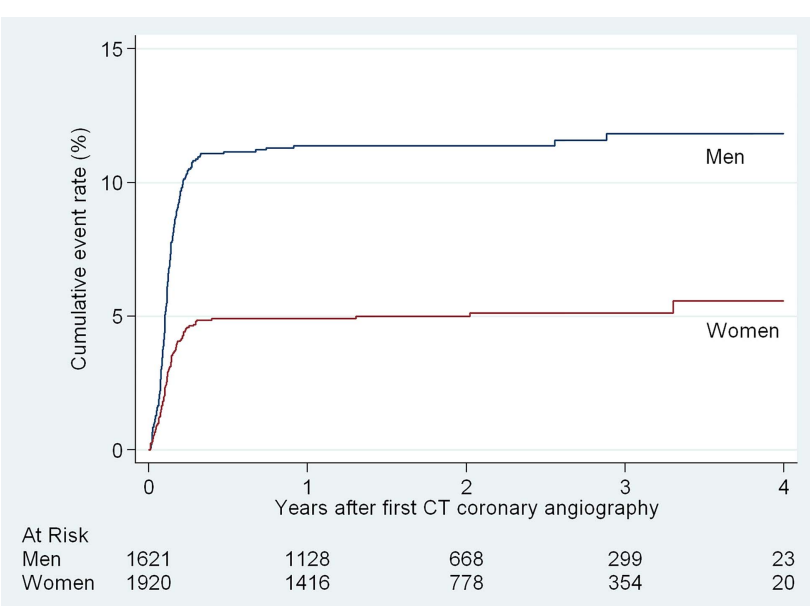

Figure 2 Cumulative rate of coronary revascularisation by sex.

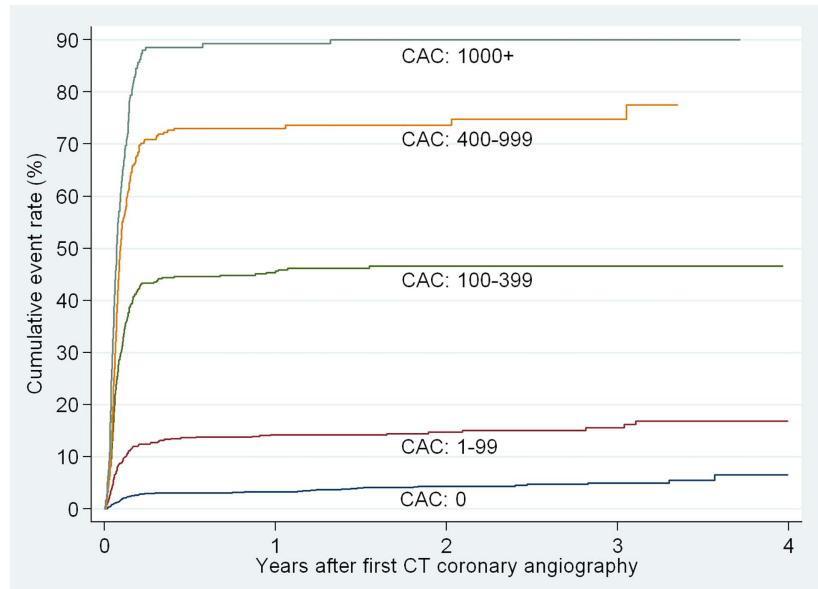

Figure 3 Cumulative rates of invasive coronary angiography by category of coronary artery calcium score (CAC).

risk of coronary revascularisation was reduced in women, irrespective of CAC. Surprisingly, the median CAC score was 0 in our female patient population. This is the same as the age-corresponding value reported for white women who were clinically free of apparent cardiovascular disease in the Multi-Ethnic Study of Atherosclerosis. ${ }^{6}$ The Framingham Heart Study also found an age-corresponding median CAC score of 0 in women. $^{11}$

Emergency department evaluation by CCTA of patients admitted with symptoms suggestive of acute coronary syndrome found that only $5 \%$ of women had signs of obstructive coronary heart disease versus $17 \%$ of men. ${ }^{12}$ Registry-based studies in the USA reported that women undergoing elective invasive coronary angiography in contemporary clinical practice had a lower prevalence of obstructive coronary heart disease than men. ${ }^{13} 14$ This indicates that the prevalence of coronary

Table 3 Cox proportional HRs with $95 \% \mathrm{Cl}$ for the association between gender and risk of invasive coronary angiography and risk of coronary revascularisation after coronary CT angiography

\begin{tabular}{ll}
\hline Risk & $\begin{array}{l}\text { HR (95\% CI) } \\
\text { for women } \\
\text { (reference men) }\end{array}$ \\
\hline Risk of invasive coronary angiography & \\
Age-adjusted & $0.52(0.45$ to 0.59$)$ \\
CAC-score-adjusted & $0.98(0.85$ to 1.13$)$ \\
Age- and CAC-score-adjusted & $1.00(0.86$ to 1.15$)$ \\
Multiple adjusted model & $1.00(0.85$ to 1.16$)$ \\
Risk of coronary revascularisation & \\
Age-adjusted & $0.36(0.28$ to 0.46$)$ \\
CAC-score-adjusted & $0.73(0.57$ to 0.93$)$ \\
Age- and CAC-score-adjusted & $0.70(0.54$ to 0.90$)$ \\
Multiple adjusted model &
\end{tabular}

${ }^{*}$ Adjusted for age, CAC score, smoking, diabetes mellitus, treatment for hypertension and cholesterol-lowering treatment. $\mathrm{CAC}$, coronary artery calcium. 
heart disease among women with chest pain is low in general practice, chest pain clinics, cases of elective invasive coronary angiography, and emergency departments. However, this may not imply that CCTA should not be used, because CCTA has been shown to be cost-effective in the diagnostic evaluation of patients with a low to intermediate pretest probability of coronary heart disease, ${ }^{15}$ although cost-effectiveness analysis did not stratify by sex.

It has been reported that women are more likely than men to present with symptoms of cardiovascular disease that might also be caused by an anxiety disorder. ${ }^{16}{ }^{17}$ A primary focus on chest discomfort without considering the full constellation of symptoms may result in inadvertently overlooking anxiety as a diagnostic consideration. ${ }^{16}$

\section{Strengths and limitations of the study}

Data were collected prospectively, but examined in retrospect, which prevented observer bias. The Western Denmark Heart Registry receives information on vital status on a daily basis from the Danish Civil Registration System. The Western Denmark Heart Registry further secures a high degree of completeness and validity with respect to CCTA, invasive coronary angiography and coronary revascularisation. ${ }^{8} 9$ Our single-centre findings need independent replication. Some patients had data missing. However, statistical analyses indicated that patients with missing data did not differ from patients with complete data, suggesting that missing data was a random occurrence rather than a systematic error. The decision to revascularise can depend on factors that we have not captured, such as, for example, differential preference by sex. We had no information on emigration status, but differential emigration by CAC score is unlikely.

We had no detailed information on symptom characteristics, duration and severity. During the study period, functional diagnostics during coronary angiography such as measurement of fractional flow reserve for classification of the haemodynamic significance of a coronary stenosis was implemented to determine the need for revascularisation. ${ }^{18}$ This occurred late in the study period because the clinical significance of fractional flow reserve measurement was first recognised and published only during the third year of our study period. ${ }^{10}{ }^{18}$ We cannot exclude the possibility that measuring fractional flow reserve in all patients would have abolished our finding that women had a lower CAC-adjusted risk of coronary revascularisation than men. More extensive use of perfusion scans may have also affected gender-specific risks of coronary revascularisation.

\section{CONCLUSIONS}

We found that women had a lower CAC score and underwent less invasive coronary angiography and revascularisation than men. However, in multivariable models, we found that CAC rather than gender determined the use of invasive coronary angiography after CCTA, although the risk of coronary revascularisation was reduced in women, irrespective of CAC. The process of triaging women with chest pain needs further scientific investigation.

Acknowledgements We are grateful to Leif Spange Mortensen, MSc for critical evaluation of the manuscript.

Contributors KSN, CI, JSB, JKJ, AHN, AN, GU, JSL and LF all participated in the original conception and design of the study. KSN and LF were involved in the data analysis and interpretation. KSN, Cl, JSB, JKJ, AHN, AN, GU, JSL and LF participated in interpretation of the data, as well as drafting and critical review of the paper. KSN takes responsibility for the overall content as guarantor.

Funding Diagnostic Centre, Silkeborg Hospital, Denmark.

Competing interests None declared.

Ethics approval The study was approved by the Danish Data Protection Agency.

Provenance and peer review Not commissioned; externally peer reviewed.

Open Access This is an Open Access article distributed in accordance with the Creative Commons Attribution Non Commercial (CC BY-NC 4.0) license, which permits others to distribute, remix, adapt, build upon this work noncommercially, and license their derivative works on different terms, provided the original work is properly cited and the use is non-commercial. See: http:// creativecommons.org/licenses/by-nc/4.0/

\section{REFERENCES}

1. Detrano R, Guerci AD, Carr JJ, et al. Coronary calcium as a predictor of coronary events in four racial or ethnic groups. $N$ Engl J Med 2008;358:1336-45.

2. Agatston AS, Janowitz WR, Hildner FJ, et al. Quantification of coronary artery calcium using ultrafast computed tomography. J Am Coll Cardiol 1990;15:827-32.

3. Shaw LJ, Raggi P, Berman DS, et al. Coronary artery calcium as a measure of biologic age. Atherosclerosis 2006;188:112-19.

4. Schmermund A, Erbel R, Silber S, MUNICH Registry Study Group. Multislice Normal Incidence of Coronary Health. Age and gender distribution of coronary artery calcium measured by four-slice computed tomography in 2,030 persons with no symptoms of coronary artery disease. Am J Cardiol 2002;90:168-73.

5. Allison MA, Wright CM. Age and gender are the strongest clinical correlates of prevalent coronary calcification (R1). Int J Cardiol 2005;98:325-30.

6. McClelland RL, Chung H, Detrano R, et al. Distribution of coronary artery calcium by race, gender, and age: results from the Multi-Ethnic Study of Atherosclerosis (MESA). Circulation 2006;113:30-7.

7. Budoff MJ, Nasir K, McClelland RL, et al. Coronary calcium predicts events better with absolute calcium scores than age-sex-race/ ethnicity percentiles: MESA (Multi-Ethnic Study of Atherosclerosis). J Am Coll Cardiol 2009;53:345-52.

8. Schmidt M, Maeng M, Jakobsen CJ, et al. Existing data sources for clinical epidemiology: The Western Denmark Heart Registry. Clin Epidemiol 2010;2:137-44.

9. Nielsen LH, Norgaard BL, Tilsted HH, et al. The Western Denmark Cardiac Computed Tomography Registry: a review and validation study. Clin Epidemiol 2015;7:53-64.

10. Norgaard KS, Isaksen C, Buhl JS, et al. CT coronary angiography in low- to intermediate-risk patients: less radiation, less invasive angiography, and less revascularisation. Scand Cardiovasc $J$ 2014;48:265-70.

11. Hoffmann U, Massaro JM, Fox CS, et al. Defining normal distributions of coronary artery calcium in women and men (from the Framingham Heart Study). Am J Cardiol 2008;102:1136-41, 1141.e1.

12. Truong QA, Hayden D, Woodard PK, et al. Sex differences in the effectiveness of early coronary computed tomographic angiography compared with standard emergency department evaluation for acute chest pain: the rule-out myocardial infarction with Computer-Assisted Tomography (ROMICAT)-II Trial. Circulation 2013;127:2494-502. 
13. Patel MR, Peterson ED, Dai D, et al. Low diagnostic yield of elective coronary angiography. N Engl J Med 2010;362:886-95.

14. Patel MR, Dai D, Hernandez AF, et al. Prevalence and predictors of nonobstructive coronary artery disease identified with coronary angiography in contemporary clinical practice. Am Heart $J$ 2014; 167:846-852.e2.

15. Zeb I, Abbas N, Nasir K, et al. Coronary computed tomography as a cost-effective test strategy for coronary artery disease assessmenta systematic review. Atherosclerosis 2014;234:426-35.
16. Carmin CN, Ownby RL, Wiegartz PS, et al. Women and non-cardiac chest pain: gender differences in symptom presentation. Arch Womens Ment Health 2008;11:287-93.

17. Bosner S, Haasenritter J, Hani MA, et al. Gender differences in presentation and diagnosis of chest pain in primary care. BMC Fam Pract 2009;10:79.

18. De Bruyne B, Pijls NH, Kalesan B, et al. Fractional flow reserve-guided $\mathrm{PCl}$ versus medical therapy in stable coronary disease. N Engl J Med 2012;367:991-1001. 